\title{
Evaluation of Acitretin in The Treatment of Multiple Recalcitrant Common Warts: a Pilot Study
}

Eleni Tzouveka*

Sygros Hospital, Athens, Greece

\begin{abstract}
Morphea, also known as Localized scleroderma, is an idiopathic often self-limited, inflammatory disorder that causes fibrotic changes in the skin. Fibrotic, asymmetric plaques, usually $2-15 \mathrm{~cm}$ wide, characterize the disease. The active lesions may have erythematous or violaceous borders, whereas the inactive ones may result to hyperpigmentation. The thickening may expand to the subcutaneous tissue or may be to the lower layers of the skin, causing dysfunction at certain levels. There is no relevance to any systematic disease. Morphea usually evolves for several years and then degrades.
\end{abstract}

\section{Introduction}

Morphea or Localized Scleroderma is a disorder characterized by excessive deposition of collagen, resulting in thickening of the skin, the subcutaneous tissue, or both [1-4]. Morphea can be categorized to certain types:

- Plaque-type morphed,

- Generalized morphea,

- Linear morphea and

- Morphea profunda,

depending on the clinical features and the depth of tissue that the disease affects $[5,6]$.

The alterations in localized scleroderma, unlike the systemic, are limited to the skin [7]. Patients with morphea do not present with Raynaud's phenomenon or sklerodaktyly and development to systemic scleroderma is rare $[8,9]$.

\section{Epidemiology}

Morphea is a relatively uncommon disorder that affects adults and children [10]. The incidence of the disease is $2.7 / 100,000$ people in the general population, and the prevalence of the disease increases with age [11]. The male to female ratio is $1: 3$, apart from the linear form, where the disease affects both sexes equally $[12,13]$. It occurs more frequently in Caucasians and Asians compared to African-Americans. The onset of the disease in most patients is between 20-50 years, and may rarely occur in childhood, while the linear form often occurs in children and adolescents [with two thirds of the cases earlier than 18 years of age] $[14,15]$.

Localized scleroderma is a benign self-limiting disease, whose active phase is estimated to take from 3 to 6 years. The survival rate was not different from that of the general population. Nevertheless, the linear and the deep types of morphea may cause some degree of dysfunction, when it appears before the age of 18 [16].

\section{Etic-pathogenesis}

The overproduction of collagen by fibroblasts in the affected tissues is a common feature of all types of scleroderma, although the fibroblast activation mechanism is still unknown $[17,18]$. Currently it is believed that the pathogenesis of skin hardening is based on three factors: vascular disorder, activated T-cells and the disruption of fibroblasts to produce connective tissue $[19,20]$.

The endothelial cells' injury is believed to trigger the disease pathogenesis. This results in the creation of adhesion molecules and T-helper 2 cytokines, such as interleukins IL- 4 and IL-6, and transforming growth factor-beta [TGF- $\beta$ ]. These cytokines result in mobilization of eosinophils, the CD4 + T-cells and macrophages, which are present in early lesions of the disease and the Eosinophilic fasciitis $[21,22]$. Cytokines along with growth factors increase fibroblastic activity and induce further collagen synthesis and connective tissue [23]. The latter is a soluble mediator, which increases and maintains the activity of TGF- $\beta$ in the stimulation of fibroblasts. The final result of the endothelial injury and the inflammatory cascade that follows is the increase of collagen and the deposition of extracellular matrix [24-26].

The causes of the disease are unknown [27]. An immune mechanism has been proposed due to the detection of autoantibodies. There are some indications of Morphea development, following B. burgdorferi infection, measles and chickenpox [28,29]. Other possible causes of the disease onset include post-trauma inflammation, vaccination with BCG, parenteral administration of vitamin B, radiotherapy, chimerism, certain drugs [penicillamine, bromocriptine, etc.] $[9,30]$.

\section{Clinical Features}

Both localized and generalized scleroderma has slow evolution and more often affect the trunk. Linear scleroderma is more common in children younger than 10 years and extremities are mainly affected [31]. Apart from scleroderma, en coupe de sabre and progressive facial hemiatrophy, there is no involvement of the face and the extremities, contrary to what takes place in systemic scleroderma [32].

- Plaque-type morphea: It is the most common type of localized scleroderma. The typical lesion occurs suddenly, as a slightly infiltrated erythematous or violaceous plaque with swelling, which extends to the periphery [33]. It is asymptomatic and often not taken into consideration by the patient. The center of the lesion gradually presents hardening and scarring. Depending on the depth affected, the skin gradually hardens. The center of the lesion may obtain a glossy white color [color ivory] surrounded by a reddish halo [lilac ring]. This

*Corresponding author: Eleni Tzouveka, Sygros Hospital, Athens, Greece, Tel: 210 7265100; E-mail: theodoroschatzitheodorou@gmail.com

Received April 20, 2015; Accepted May 10, 2015; Published May 25, 2015

Citation: Tzouveka E (2015) Evaluation of Acitretin in The Treatment of Multiple Recalcitrant Common Warts: a Pilot Study. Pigmentary Disorders 2: 185. doi:10.4172/2376-0427.1000185

Copyright: () 2015 Tzouveka E. This is an open-access article distributed under the terms of the Creative Commons Attribution License, which permits unrestricted use, distribution, and reproduction in any medium, provided the original author and source are credited. 
feature is an indication that the disease is in progress. Post inflammatory pigmentation is often present. The hair follicles and sweat glands may appear atrophic [34]. The lesions may be pruritic and may present paresthetic. The plaques are usually $2-15 \mathrm{~cm}$ in diameter, multiple and asymmetric. It may increase significantly or remain constant in size. The most common site Plaque type morphea develops is the trunk. The evolution of the disease varies. In most patients progress takes more than 5.3 years and then may switch to resting phase, whereas in other patients may result to spontaneous healing.

- Guttate morphea: Occurs mainly as multiple and usually superficial nummular plaques. Although relatively small, they usually become sclerotic and most commonly found in the neck and upper trunk [35]. The lesions are less than $10 \mathrm{~mm}$ in diameter, well circumscribed in white and surrounded by red-violaceous halos, without induration but tend to conglomerate and atrophy [36-38]. This type clinically resembles the lichen sclerosus et atrophicus [39].

- Atrophoderma of Pasini and Pierini: It can usually be found in many patients with localized scleroderma and presents with oval, reddish-violaceous or reddish-brown color, macules or plaques $[40,41]$. These lesions are marked by a slight depression of the skin with an abrupt edge, unlike plaque-type morphea $[42,43]$. They are mainly located in the rear part of the trunk and sometimes the lesions may follow the lines of Blaschko [44-47].

- Deep morphea [morphea profunda]: is a type of form that mainly affects the dermis and the subcutaneous tissue and may even affect underlying layers [eg, fascia] [48]. Patients usually present with a single or a few hard plaques in the deep tissues, allowing image "pseudocellulitis" and progressively, the lesions may become calcified, leading to osteoma cutis [49]. The distribution of the lesions is usually symmetrical and these are usually hyperpigmented, but because of deep inflammation, they do not acquire the typical variations of color, as in plaque form type. Because of the distribution of the sclerosis, individual lesions may present with certain clinical features found in eosinophilic fasciitis $[50,51]$.

- Nodular or Keloid morphea: Rare variant form, in which inflammation of the dermis leads to thickened nodules that look like keloids, in the presence of typical plaque-type morphea $[2,52,53]$.

- Bullous morphea: Rare variant form in which hypoepidermic, tensed bulla, is created under the lesions of the sclerotic, linear or deep forms [54]. This phenomenon may come as a result of the stasis of the lymph due to sclerosing process or coexistent lichen sclerosus et atrophicus [55].

- Linear morphea: The lesion manifests as morphea-form plaques arranged in a linear distribution, but more often confluent plaques, which extend vertically and may reduce the mobility of the affected extremity. The lesion is solitary and usually found in the extremities, tends to include the underlying fascia, muscle and tenants. This leads both to muscle weakness and gradually to the reduction of the muscle and fascia and ultimately to the reduction of the joint mobility. When other joints are infected, functional disorders and deformities, that can lead to impotence may occur $[11,16]$. A particularly rare form, which occurs in black African is "Inhume", which is presented as a surrounding the limb or a finger band. In "Ainhum" a fibrous ring is automatically produced, which results in amputation of the digit [50].

- Scleroderma en coupe de sabre: It is a clinical form of linear scleroderma. The damage resembles the original band or confluent small plaques, extending from the forehead upwards [56]. Initially, as the plaques form, surrounded by reddish-violaceous halo, the sclerosis extends vertically and can extend to the eyebrows, the nose, even the cheeks. It is mainly located unilateral and most often paramedian of the face. These lesions may extend deep to underlying muscles and bones, but very rare in the meninges or even the brain. It is possible to observe hair loss and scarring alopecia. Finally, the lesion develops into sclerotic or atrophic [57]. The most common neurological complication of the disease is epilepsy, in about $10 \%$ of the patients. Other complications may be ocular or aural [58].

The Parry-Romberg syndrome [progressive face hemiatrophy] is probably a severe variant of the linear form, but may also occur as a primary atrophic disorder [59,60]. Appears with small or no sclerosis [separates from morphea en coupe de sabre] and affects the trigeminal nerve throughout its course, resulting in disruption of the eye and tongue, with possible hypoplasia of the jaw $[61,62]$.

- Generalized morphea: is the most severe clinical form of morphea. Characterized by multiple lesions at various stages of development, often accumulated and occupy larger areas of the body [three or more anatomical regions], such as the sternum, the abdomen, the waist, the buttocks, etc., or even the entire surface of the trunk. The color varies from hyperpigmented to silver [63].

- Disabling pansclerotic morphea of children: is a rare, serious and amputating form, involving the dermis, subcutaneous fat, fascia, muscles and even bones in children less than 14 years old. It can lead to serious deformities of the joints and skin ulcerations [64].

\section{Extracutaneous Manifestations}

Usually patients with localized scleroderma do not mention other symptoms, except skin lesions. Fever, regional case lymphadenopathy, arthralgia, headaches, epigastric pain, neuralgia, etc. have been reported $[32,65]$.

\section{Diagnosis}

A] Laboratory findings: In localized scleroderma, laboratory tests may not be accompanied by pathological findings. Sometimes eosinophilia may be observed, which relates to the progress of the disease, as well as increased immunoglobulins, mainly IgG. In $26 \%$ of patients, the rheumatoid factor is positive, while E.S.R is increased in $25 \%$ of the patients. In generalized and linear morphea, antinuclear antibodies are positive in $40-80 \%$ of patients and $35-50 \%$ have positive anti-ssDNA antibodies and / or histone antibodies [66,67].

B] Histological image: Best to be divided into two stages: the early or inflammatory and late or sclerotic stage. In the early stage, dermis can be found tumorous, whereas the collagen fibers are homogenized with eosinophilia [68]. Lymphocytic inflammatory infiltration is observed around the vessels, which expands in the subcutaneous fat. In the late stage, thickening of the dermis and reduction of the inflammatory lymphocytic infiltration is observed, with plenty of fibroblasts [69]. The collagen fibers are thicker, hypertrophic and homogenized. Hair, as long as sebaceous glands, is disappeared and, sometimes, only the muscle arrester pili of the hair are found, along with atrophy of the skin [70].

\section{Differential Diagnosis}

Diagnosis is based on clinical findings and sometimes can be confirmed by skin biopsy [71]. The differential diagnosis involves the systemic sclerosis, the lichen sclerosus et atrophicus, eosinophilic fasciitis, Buschke scleroderma, late cutaneous porphyria, the pleudoscleroderma and Lyme disease [B.burgdorferi infection] etc. [32]. 


\section{Treatment}

Treatment of localized scleroderma aims to reduce inflammation in the active initial phase of the disease rather than the late phase, where the lesions are already established [31,72]. In several cases, the disease does not need any treatment since it is self-healing in 3-5 years $[70,73]$.

\section{- Local therapy:}

o topical potent corticosteroids (clompetasol propionate cream $0.05 \%$ for $12-24$ weeks) or intralesional injections of triamcinolone, in order to reduce the inflammatory process and inhibit further progression.

o calcineurin inhibitor, as a tacrolimus $0.1 \%$ ointment, twice a day for 12 weeks proves effective.

o calcipotriol ointment $0.005 \%$, in in vitro studies, inhibits proliferation of cultured fibroblasts used in the treatment of localized scleroderma [74]. Good results have been reported using calcipotriol topically with betamethasone dipropionate $[75,76]$.

- Systemic treatment:

o Immunosuppressants: oral corticosteroids [methylprednisolone $1-2 \mathrm{mg} / \mathrm{kg} /$ day] may help the inflammatory stage of the disease, but has little efficacy in established sclerosis. Otherwise, in the acute phase of the disease, $15-20 \mathrm{mg} /$ week of methotrexate may be useful. Few studies report the improvement of the disease after using cyclosporine [77].

o antifibrotic agents, such as D-penicillamine, which firstly inhibit the production of polythydroxylasis by the fibroblasts of collagen and therefore the composition of it, and secondly participates in the collagen degradation, activating the collagenase.

o Antimalarial, phenytoin, colchicine have been used in generalized form with mediocre results.

- Phototherapy: it can be very effective as first-line therapy in generalized form, or even as a second line at a late stage of the disease, if we take into consideration the minimum side effects, compared to the immunosuppressive agents. Ultraviolet A broad band [UVAbb 320-400 nm] [78] and psoralens with UVA (oral or bath) or photochemotherapy (PUVA) have been used with significant clinical improvement of lesions [79]. Also, UVA-1, since it penetrates deeper into the epidermis, has been proven a very effective therapy in Morphea $[80,81]$. Ultraviolet B radiation narrow band [UVBnb] may also have results, even though it is not able to penetrate the deeper layers of the epidermis, as good as the UVA-1 $[82,83]$.

The protocols that combine treatment with ultraviolet light and topical corticosteroids or calcipotriol may have better results instead of each therapy standing alone $[75,84]$.

- Other approaches to treatment aim at the modification of the action of cytokines, but studies are still to be carried out. These include topical administration of halofuginone (which synthesis the inhibitor of transforming growth factor $b$, TGF- $\beta$ ), inhibitors of TNF- $\alpha$ and thalidomide. A randomized double-blind study showed no improvement of lesions after administering INF- $\gamma$.

- Other systems

o Orthopedic treatment in any deformation of joints.

o Plastic surgery to correct deformities, due to atrophy of the subepidermal tissue.

o Physiotherapy in patients with muscle weakness. o Ophthalmology, neurological, dental treatment, depending on the affected system $[85,16]$.

\section{Prognosis and Clinical Course}

Most forms of localized scleroderma are self-limited and the activity of the lesions is estimated to last average 3-5 years and low activity for many years. In some patients, reactivation of inactive lesions may be observed. Despite the autoantibodies found in the patients' serum, localized scleroderma does not present in a systemic form, even though a very rare coexistence with other disease of the connective tissue has been reported. A small-extent atrophy, with or without hyperpigmentation, may be the only sign of the disease.

\section{References}

1. Baker LA, Jacobe HT (2014) Scleroderma and Morphea. Dermatology Atlas for Skin of Color. Springer 167-173.

2. Barzilai A, Lyakhovitsky A, Horowitz A, Trau H (2003) Keloid-like scleroderma Am J Dermatopathol 25: 327-330.

3. Canady J, Karrer S, Fleck M, Bosserhoff AK (2013) Fibrosing connective tissue disorders of the skin: molecular similarities and distinctions. J Dermatol Sci 70 151-158.

4. Aberer E, Klade H, Hobisch G (1991) A clinical, histological, and immunohistochemical comparison of acrodermatitis chronica atrophicans and morphea. Am J Dermatopathol 13: 334-341.

5. Bielsa Marsol I (2013) Update on the classification and treatment of localized scleroderma. Actas Dermosifiliogr 104: 654-666.

6. Peterson LS, Nelson AM, Su WP (1995) Classification of morphea (localized scleroderma). Mayo Clin Proc 11: 1068-1076.

7. CHRISTIANSON HB, DORSEY CS, KIERLAND RR, O'LEARY PA (1956) Localized scleroderma; a clinical study of two hundred thirty-five cases. AMA Arch Derm 74: 629-639.

8. Fett N WV (2010) Epidemiology, clinical presentation and pathogenesis outcome measures and treatment.

9. Jacobe H, Callen J, Ofori AO (2011) Pathogenesis, clinical manifestations, and diagnosis of morphea (localized scleroderma) in adults.

10. Mayes MD (1997) Epidemiology of systemic sclerosis and related diseases. Curr Opin Rheumatol 9: 557-561.

11. Fett N, Werth VP (2011) Update on morphea: part I. Epidemiology, clinica presentation, and pathogenesis. J Am Acad Dermatol 64: 217-228.

12. Fleischmajer R (1977) The pathophysiology of scleroderma. Int J Dermatol 16: 310-318.

13. Peterson LS, Nelson AM, Su WP, Mason T, O'Fallon WM, et al. (1997) The epidemiology of morphea (localized scleroderma) in Olmsted County 19601993. J Rheumatol 24: 73-80.

14. Fleischmajer R, Nedwich A (1972) Generalized morphea. I. Histology of the dermis and subcutaneous tissue. Arch Dermatol 106: 509-514.

15. Hawk A, English JC 3rd. (2001) Localized and systemic scleroderma. Seminars in cutaneous medicine and surgery WB Saunders 1: 27-37.

16. Fett N, Werth VP (2011) Update on morphea: part II. Outcome measures and treatment. J Am Acad Dermatol 64: 231-242.

17. Campbell PM, LeRoy EC (1975) Pathogenesis of systemic sclerosis: a vascular hypothesis. Semin Arthritis Rheum 4: 351-368.

18. Sternberg EM (1985) Pathogenesis of scleroderma: the interrelationship of the immune and vascular hypotheses. Surv Immunol Res 4: 69-80.

19. Greenblatt MB, Aliprantis AO (2013) The immune pathogenesis of scleroderma: context is everything. Curr Rheumatol Rep 15: 297.

20. Penny R (1978) Scleroderma: pathogenic factors and current management. Aust N Z J Med 8 Suppl 1: 143-148.

21. Haxthausen $H$ (1947) Studies on the pathogenesis of morphea, vitiligo and acrodermatitis atrophicans by means of transplantation experiments. Acta Derm Venereol 27: 352-368. 
Citation: Tzouveka E (2015) Evaluation of Acitretin in The Treatment of Multiple Recalcitrant Common Warts: a Pilot Study. Pigmentary Disorders 2: 185. doi:10.4172/2376-0427.1000185

Page 4 of 5

22. Peters MS, Su WP (1991) Eosinophils in lupus panniculitis and morphea profunda. J Cutan Pathol 18: 189-192.

23. O'Loughlin S, Tappeiner G, Jordon RE (1980) Circulating immune complexes in systemic scleroderma and generalized morphea. Dermatologica 160: 25-30.

24. Hayashi M, Ichiki Y, Kitajima Y (2009) Coexistence of recurrent generalized morphea and systemic sclerosis. Acta Derm Venereol 89: 329-330.

25. Khaled A, Kharfi M, Zaouek A, Rameh S, Zermani R, et al. (2012) Postvaccination morphea profunda in a child. Pediatr Dermatol 29: 525-527.

26. Ruocco V, Ruocco E, Piccolo V, Brunetti G, Guerrera LP, et al. (2014) The immunocompromised district in dermatology: A unifying pathogenic view of the regional immune dysregulation. Clin Dermatol 32: 569-576.

27. Lee EB, Anhalt GJ, Voorhees JJ, Diaz LA (1984) Pathogenesis of scleroderma Current concepts. Int J Dermatol 23: 85-89.

28. De Vito JR, Merogi AJ, Vo T, Boh EE, Fung HK, et al. (1996) Role of Borrelia burgdorferi in the pathogenesis of morphea/scleroderma and lichen sclerosus et atrophicus: a PCR study of thirty-five cases. J Cutan Pathol 23: 350-358.

29. Dillon WI, Saed GM, Fivenson DP (1995) Borrelia burgdorferi DNA is undetectable by polymerase chain reaction in skin lesions of morphea, scleroderma, or lichen sclerosus et atrophicus of patients from North America. Journal of the American Academy of Dermatology 33: 617-620.

30. Harris ML, Rosen A (2003) Autoimmunity in scleroderma: the origin pathogenetic role, and clinical significance of autoantibodies. Curr Opin Rheumatol 15: 778-784.

31. Cory RC, Clayman DA, Faillace WJ, McKee SW, Gama CH (1997) Clinical and radiologic findings in progressive facial hemiatrophy (Parry-Romberg syndrome). AJNR Am J Neuroradiol 18: 751-757

32. James W.D BTG, Elston D.M (2011). Andrews' diseases of the skin: Clinical dermatology. (11th edn), ElsevierBacterial infections.

33. Vasquez R, Sendejo C, Jacobe H (2012) Morphea and other localized forms of scleroderma. Curr Opin Rheumatol 24: 685-693.

34. Ralf Paus, Natsuho Ito, Masahiro Takigawa, Taisuke Ito (2003) The hair follicle and immune privilege. Journal of Investigative Dermatology Symposium Proceedings, Nature Publishing Group.

35. Wolff K GLA, Katz S.I, Gilchrest B.A, Paller A.S, Leffell D.J. (2008) Fitzpatrick's Dermatology in General Medicine(7th edition), McGraw-Hill,USA.

36. Bulat V, Itum M, Mari IG, kudar VL, Kova evi M. (2014) Idiopathic Guttate Hypomelanosis: A Comprehensive Overview. Pigmentary Disorders 1: 23762378.

37. Saleh Z, Arayssi T, Saleh Z, Ghosn S (2009) Superficial morphea: 20-year follow up in a patient with concomitant psoriasis vulgaris. J Cutan Pathol 36 : 1105-1108.

38. Rook A WDS, Edling FJC (2010)Rook's Textbook of Dermatology.

39. Pope E, Laxer RM2 (2014) Diagnosis and management of morphea and lichen sclerosus and atrophicus in children. Pediatr Clin North Am 61: 309-319.

40. Buechner SA, Rufli T (1994) Atrophoderma of Pasini and Pierini. Clinical and histopathologic findings and antibodies to Borrelia burgdorferi in thirty-four patients. J Am Acad Dermatol 30: 441-446.

41. KEE CE, BROTHERS WS, NEW W (1960) Idiopathic atrophoderma of Pasini and Pierini with coexistent morphea. A case report. Arch Dermatol 82: 100-103.

42. Berman A, Berman GD, Winkelmann RK (1988) Atrophoderma (Pasini-Pierini) Findings on direct immunofluorescent, monoclonal antibody, and ultrastructural studies. Int J Dermatol 27: 487-490.

43. Jablonska S, Blaszczyk M (2004) Is superficial morphea synonymous with atrophoderma Pasini-Pierini? J Am Acad Dermatol 50: 979-980.

44. Karaca NE, Aksu G, Karaca E, Tuzun F, Gunes AT et al (2011). Progressive morphea of early childhood tracing Blaschko lines on the face: involvement of $X$ chromosome monosomy in pathogenesis and clinical prognosis. Int $\mathrm{J}$ dermato 50: $1406-1410$

45. Kencka D, Blaszczyk M, Jabłońska S. (1995) Atrophoderma Pasini-Pierini is a primary atrophic abortive morphea. Dermatology 190: 203-206.

46. Murphy PK, Hymes SR, Fenske NA (1990) Concomitant unilateral idiopathic atrophoderma of Pasini and Pierini (IAPP) and morphea. Observations supporting IAPP as a variant of morphea. Int J Dermatol 29: 281-283.
47. Rosario C, Garelick D, Greenberg G, Chapman J, Shoenfeld Y, et al. (2015) Plaque morphea with neurological involvementâ€"an extraordinary uncommon presentation. Clin Rheumatol 34: 597-601.

48. Sayama K, Chen M, Shiraishi S, Miki Y (1991) Morphea profunda. Int J Dermatol 30: 873-875.

49. Deep morphea(2007) Seminars in cutaneous medicine and surgery, WB Saunders, UK

50. Bolognia J JJ, Rapini (2008) Dermatology (2nd edition), UK.

51. Su WP, Person JR (1981) Morphea profunda. A new concept and a histopathologic study of 23 cases. Am J Dermatopathol 3: 251-260.

52. Rencic A, Brinster N, Nousari CH (2003) Keloid morphea and nodula scleroderma: two distinct clinical variants of scleroderma? Journal of Cutaneous Medicine and Surgery: Incorporating Medical and Surgical Dermatology 7: 2024.

53. Sen S, Biswas T, Banerje G, Biswas S (2013) Keloids in scleroderma-keloidal scleroderma: a unique entity. Indian J Dermatol 58: 153-154.

54. Daoud MS, Su WP, Leiferman KM, Perniciaro C (1994) Bullous morphea: clinical, pathologic, and immunopathologic evaluation of thirteen cases. J Am Acad Dermatol 30: 937-943.

55. Kavala M, Zindanci I, Demirkesen C, Beyhan EK, Turkoglu Z (2007) Intertriginous bullous morphea: A clue for the pathogenesis? Indian J Dermato Venereol Leprol 73: 262-264

56. Jun JH, Kim HY, Jung HJ, Lee WJ, Lee SJ, et al. (2011) Parry-romberg syndrome with en coup de sabre. Ann Dermatol 23: 342-347.

57. Holland KE, Steffes B, Nocton JJ, Schwabe MJ, Jacobson RD, et al. (2006) Linear scleroderma en coup de sabre with associated neurologic abnormalities. Pediatrics 117: e132-136.

58. Flores-Alvarado DE, Esquivel-Valerio JA, Garza-Elizondo M, Espinoza LR (2003) Linear scleroderma en coup de sabre and brain calcification: is there a pathogenic relationship? J Rheumatol 30: 193-195.

59. El-Kehdy J, Abbas O, Rubeiz N (2012) A review of Parry-Romberg syndrome. J Am Acad Dermatol 67: 769-784

60. Tollefson MM, Witman PM (2007) En coup de sabre morphea and ParryRomberg syndrome: a retrospective review of 54 patients. J Am Acad Dermato 56: 257-263.

61. Castro-Govea Y, De La Garza-Pineda O, Lara-Arias J, Chacón-Martínez H Mecott-Rivera G, et al. (2012) Cell-assisted lipotransfer for the treatment of parry-romberg syndrome. Arch Plast Surg 39: 659-662.

62. Miller MT, Sloane H, Goldberg MF, Grisolano J, Frenkel M, et al. (1987) Progressive hemifacial atrophy (Parry-Romberg disease). J Pediatr Ophthalmo Strabismus 24: 27-36.

63. Foti R1, Leonardi R, Rondinone R, Di Gangi M, Leonetti C, et al. (2008) Scleroderma-like disorders. Autoimmun Rev 7: 331-339.

64. Diaz-Perez JL, Connolly SM, Winkelmann RK (1980) Disabling pansclerotic morphea of children. Arch Dermatol 116: 169-173.

65. Sehgal VN, Srivastava G, Aggarwal AK, Behl PN, Choudhary M, et al. (2002) Localized scleroderma/morphea. Int J Dermatol 41: 467-475.

66. de Jong EMGJ, van den Hoogen FHJ (2011) A Young Adult with Localized Skin Sclerosis and Positive ANA. Case Studies in Systemic Sclerosis, Springer London, UK.

67. Falanga V, Medsger TA Jr, Reichlin M (1987) Antinuclear and anti-singlestranded DNA antibodies in morphea and generalized morphea. Arch Dermato 123: $350-353$

68. Rahbari H (1989) Histochemical differentiation of localized morpheascleroderma and lichen sclerosus et atrophicus. J Cutan Pathol 16: 342-347.

69. R.P R(2012) Practical Dermatopathology.2nd edition, Elsevier, USA.

70. Habif T.P CLJ (2012) Skin disease Diagnosis and Treatment. (3rd edition) Elsevier Health Sciences,UK

71. Johnson W, Jacobe H (2012) Morphea in adults and children cohort II: patients with morphea experience delay in diagnosis and large variation in treatment. $J$ Am Acad Dermatol 67: 881-889.

72. Fett NM (2012) Morphea: evidence-based recommendations for treatment Indian J Dermatol Venereol Leprol 78: 135-141. 
Citation: Tzouveka E (2015) Evaluation of Acitretin in The Treatment of Multiple Recalcitrant Common Warts: a Pilot Study. Pigmentary Disorders 2: 185. doi:10.4172/2376-0427.1000185

73. Dutz J (2000) Treatment options for localized scleroderma. Skin Therapy Lett 5: $3-5$

74. Cunningham BB, Landells ID, Langman C, Sailer DE, Paller AS (1998) Topical calcipotriene for morphea/linear scleroderma. J Am Acad Dermatol 39: 211 215

75. Kreuter A, Gambichler T, Avermaete A, Jansen T, Hoffmann M, et al. (2001) Combined treatment with calcipotriol ointment and low-dose ultraviolet $A 1$ phototherapy in childhood morphea. Pediatr Dermatol 18: 241-245.

76. Tay YK (2003) Topical calcipotriol ointment in the treatment of morphea. $J$ Dermatolog Treat 14: 219-221.

77. Kreuter A, Krieg T, Worm M, Wenzel J, Gambichler T, et al. (2009) [AWMF Guideline no. 013/066. Diagnosis and therapy of circumscribed scleroderma]. J Dtsch Dermatol Ges 7 Suppl 6: S1-14

78. El-Mofty M, Mostafa W, E-Darouty M, Bosseila M, Nada H, et al. (2004) Different low doses of broad-band UVA in the treatment of morphea and systemic sclerosis. Photodermatol Photoimmunol Photomed 20: 148-156.

79. Morison WL (1997) Psoralen UVA therapy for linear and generalized morphea. J Am Acad Dermatol 37: 657-659.
80. Kreuter A, Hyun J, Stücker M, Sommer A, Altmeyer P, et al. (2006) A randomized controlled study of low-dose UVA1, medium-dose UVA1, and narrowband UVB phototherapy in the treatment of localized scleroderma. J Am Acad Dermatol 54: 440-447.

81. Kroft EB, Berkhof NJ, van de Kerkhof PC, Gerritsen RM, de Jong EM (2008) Ultraviolet A phototherapy for sclerotic skin diseases: a systematic review. $J$ Am Acad Dermatol 59: 1017-1030.

82. Eisen D, Alster TS (2002) Use of a $585 \mathrm{~nm}$ pulsed dye laser for the treatment of morphea. Dermatol Surg 28: 615-616.

83. Sator PG, Radakovic S, Schulmeister K, Hönigsmann H, Tanew A (2009) Medium-dose is more effective than low-dose ultraviolet A1 phototherapy for localized scleroderma as shown by $20-\mathrm{MHz}$ ultrasound assessment. J Am Acad Dermatol 60: 786-791.

84. Katsambas (2003) A.D LTM. European Handbook of Dermatological Treatment. (2nd edition), Springer-Verlag Berlin Heidelberg.

85. Fett N, Werth VP (2011) Update on morphea: part I. Epidemiology, clinica presentation, and pathogenesis. J Am Acad Dermatol 64: 217-228. 